\title{
Technical guidelines for participatory village mapping exercise
}

Manuel Boissière

Amy E. Duchelle
Stibniati Atmadja

Gabriela Simonet

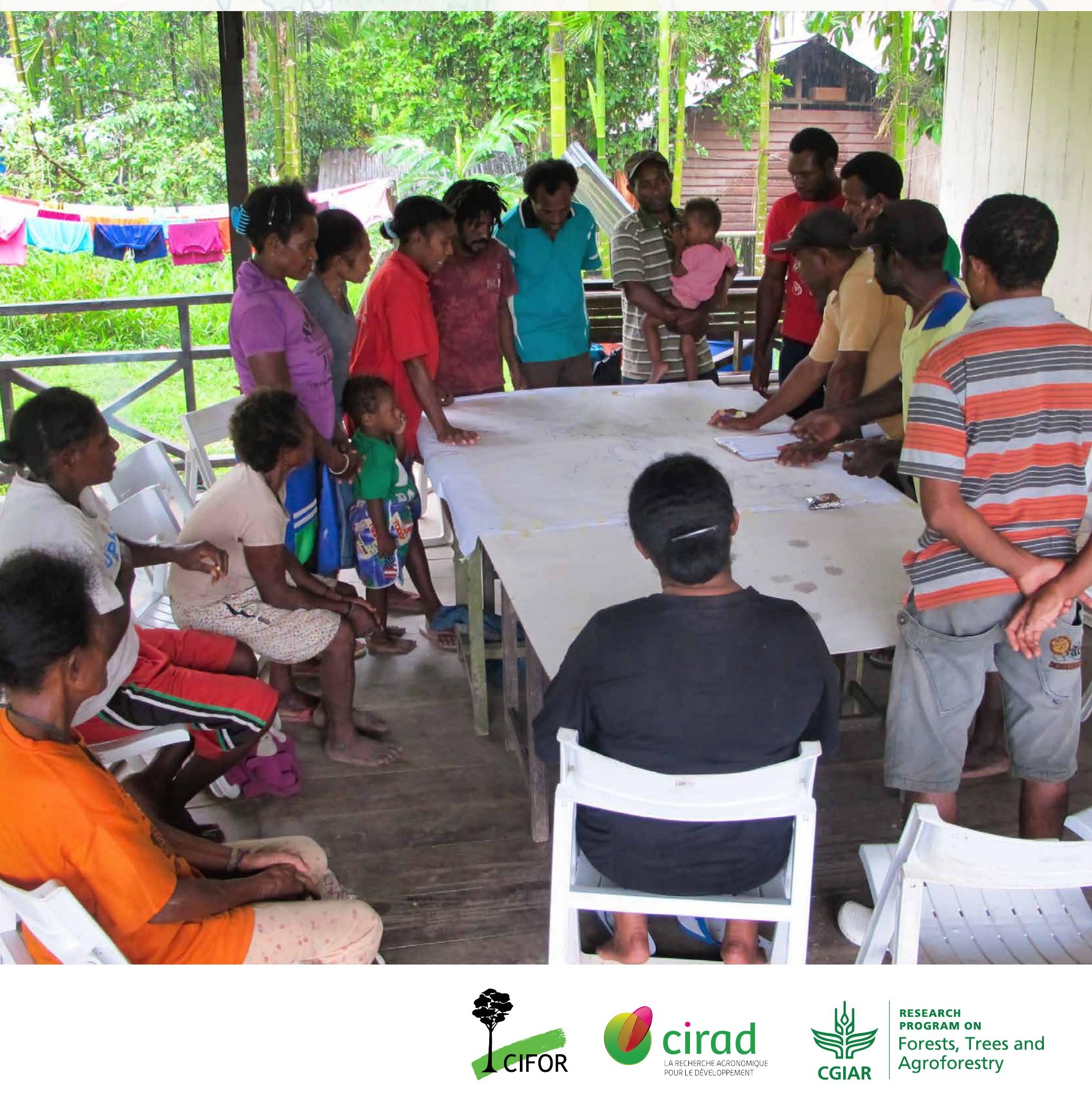





\section{Technical guidelines for participatory village mapping exercise}

Manuel Boissière

Center for International Forestry Research (CIFOR) and the French Agricultural Research Centre for International Development (CIRAD)

Amy E. Duchelle

CIFOR

Stibniati Atmadja

CIFOR

Gabriela Simonet

French National Institute for Agricultural Research (INRA) and CIFOR 
(c) 2018 Center for International Forestry Research

DOI: $10.17528 /$ cifor/007282

(c) (1) Content in this publication is licensed under a Creative Commons Attribution 4.0 International (CC BY 4.0), http://creativecommons.org/licenses/by/4.0/

Boissière M, Duchelle AE, Atmadja S and Simonet G. 2018. Technical guidelines for participatory village mapping exercise. Bogor, Indonesia: CIFOR. 19 pp.

Cover photo by Manuel Boissière

Participatory mapping in Mamberamo (Papua/Indonesia)

\author{
CIFOR \\ Jl. CIFOR, Situ Gede \\ Bogor Barat 16115 \\ Indonesia \\ $\mathrm{T}+62$ (251) 8622-622 \\ $F+62$ (251) 8622-100 \\ E cifor@cgiar.org
}

\title{
cifor.org
}

We would like to thank all donors who supported this research through their contributions to the CGIAR Fund. For a list of Fund donors please see: http://www.cgiar.org/about-us/our-funders/

Any views expressed in this publication are those of the authors. They do not necessarily represent the views of CIFOR, the editors, the authors' institutions, the financial sponsors or the reviewers. 


\section{Contents}

Acknowledgements

1 Introduction 1

2 The maps 2

2.1 The base map 2

2.2 The map from satellite imagery 2

2.3 The map on drafting paper 3

3 Checklist of materials 4

4 Mapping activity with key informants in the small discussion group 5

4.1 Preparing a copy of the base map on drafting paper before starting the activity: 5

4.2 Adding basic information on the copy of the base map on drafting paper: 6

4.3 Introducing the activity to key informants: 6

4.4 Familiarizing key informants with the map: 6

4.5 Asking key informants to update the map: 6

4.6 Asking key informants to answer the Village survey questions: 6

4.7 Finalizing the map: 7

5 Mapping activities during village and women's meetings 9

5.1 Before starting the activity with the meeting participants: 9

5.2 Preparation of the activity: 9

5.3 Familiarizing the participants with the map and requesting updates: 9

5.4 Asking the respondents to answer the survey questions: 11

$\begin{array}{ll}5.5 \text { After the group discussion: } & 11\end{array}$

6 Finalizing the maps after fieldwork $\quad 12$

$\begin{array}{ll}\text { References } & 13\end{array}$ 


\section{List of figures}

$1 \quad$ Preparing a copy of the base map on drafting paper. 5

2 Drawing landscape features with villagers on the copy of the base map using drafting paper.

3 A land tenure map on drafting paper. $\quad 8$

4 An example of a figure legend. 8

5 Participatory mapping process. 10

6 Clean map. 10

7 Workflow for the village mapping exercise. 12 


\section{Acknowledgements}

This activity is part of CIFOR's Global Comparative Study (GCS) on REDD+ (CIFOR 2017). The funding partners that have supported this study include the Norwegian Agency for Development Cooperation (Norad), the Australian Department of Foreign Affairs and Trade (DFAT), the European Commission (EC), the International Climate Initiative (IKI) of the German Federal Ministry for the Environment, Nature Conservation, Building and Nuclear Safety (BMUB), the United Kingdom Department for International Development (UKAID), and the CGIAR Research Program on Forests, Trees and Agroforestry (CRP-FTA), with financial support from the donors contributing to the CGIAR Fund. The authors would like to thank all those who have provided input and comments during the preparation of this document, and the GCS REDD+ field teams that applied these methods in the field. 



\section{Introduction}

This participatory mapping exercise was prepared for the third phase of CIFOR's Global Comparative Study (GCS) on REDD+. It is part of the research component that has evaluated the impacts of locallevel REDD+ interventions on forests and people since 2010, through a Before-After Control-Intervention (BACI) approach. Detailed methods on this research component can be found in a CIFOR publication (Sunderlin et al. 2016). This participatory mapping exercise was developed after identifying the need to have a more systematic way of documenting land use and tenure arrangements across our various field sites.

Reference is made in the present document to GCS REDD+ fieldwork, but the guidelines are meant, more generally, for researchers, field research supervisors and enumerators who have never developed maps with the participation of local communities. They are based on several documents and projects led by CIFOR using participatory mapping as one of the tools to learn about local perceptions of the landscape and local peoples' perspectives of forest and land management (van Heist 2000; Sheil et al. 2002; Anau et al. 2003; Boissière et al. 2007; Padmanaba et al. 2012; Kingsolver et al. 2017).
In the context of GCS REDD+ field research, this participatory mapping exercise provides a way to collect data on questions related to land use and tenure found in the village and women's questionnaires, and to crosscheck village boundary data that were compiled in previous research phases. In other contexts, such maps can be used as a basis for discussions on land use (Padmanaba et al. 2012), or to decide with local communities about where indepth field surveys should take place (Boissière et al. 2010).

The mapping exercise is part of three GCS REDD+ activities in each study village: (1) a small group discussion with at least three key informants to learn about village boundaries, tenure, areas under dispute, access (roads) and market location; (2) village meetings with 10-15 adult men and women; and (3) women's meetings with 10-15 adult women. The mapping exercise is conducted during the small group discussion, but the result of the initial mapping exercise is used for the village and women's meetings. 


\section{The maps}

The mapping exercise requires a base map that needs to be prepared in advance by a Geographic Information System (GIS) specialist, with village location and boundaries (as Shapefiles) obtained during the previous research phases via secondary data sources or mapping with villagers when spatial information on village boundaries was not available (see Sunderlin et al. 2016, 66-67).

Three maps are needed for the mapping exercise: a base map, a satellite image/map and a copy of the base map on drafting paper.

\subsection{The base map}

The base map is a bare-bones map, with the minimum number of features needed to orient key informants to locations of interest. The GIS specialist extracts these features from the satellite images (e.g. Landsat, Sentinel or any other free and most recent satellite images available for the different sites). The base map is printed on A0 format $(841 \times 1189 \mathrm{~mm})$ paper, which helps to include a maximum number of landmarks and names. The following list indicates a number of landmarks and other features, not exhaustive, to be included on the base map:

a. settlements position (e.g. main village, hamlets, huts)

b. roads, paths, airports/airstrips

c. religious buildings (e.g. churches, mosques, traditional houses) if visible on the satellite image (or if the position using a Global Positioning System (GPS) was provided during a previous field survey)

d. any other building known by all the villagers (e.g. government office, communal building, cooperative, school), if visible on the satellite image (or if GPS position was provided during a previous field survey)

e. rivers, streams, ponds, lakes f. mountains, peaks (visible on the map based on the satellite image, but only with an icon, for example, a triangle, on the base map)

g. geographical coordinates (use preferably Universal Transverse Mercator (UTM))

h. village boundaries identified during previous field visits.

This list can be adapted to the features considered to be important for each of the sites/countries. It is important to include all these features on the base map to make the map easily understood by the key informants and other respondents so that they know where to draw when asked by the field research supervisors/enumerators.

\subsection{The map from satellite imagery}

A map based on satellite imagery will be used to support discussions with villagers. It will have minimal interpretation, because otherwise it would be too 'busy' and time consuming to prepare. It contains the same landmarks from the base map, and the geographical coordinates are made visible to aid the digitization after fieldwork. Minimal interpretation will be done by the GIS specialist and can include areas of forest vs non-forest, settlements and water bodies. Information from satellite interpretation are only indicative, and not definitive. This map will serve to cross-reference villagers' answers to the survey questions (e.g. presence of degraded forest, areas of land conversion).

Ideally, this map is printed in color with high resolution on an A0 sheet of paper to allow overlay on the base map. The highest-resolution, cloud-free satellite images available for the study site should be used. The resulting map image should be printed using glossy paper or laminated to protect it from moisture. If too costly or 
technically difficult to print an A0 map, it can be substituted by a smaller map. We strongly recommend no smaller than A2 size. This printed map can be displayed in the village for the villagers to familiarize themselves with the map before the mapping activity, and later to identify areas where forest has been cleared.

\subsection{The map on drafting paper}

The map on drafting paper will be used to record the data provided during the small group discussion. The researcher needs to trace the geographical coordinates and all the landmarks from the base map onto the drafting paper, using permanent (waterproof) markers. During the small group discussions with key informants, the researcher will overlay the map on drafting paper on the base map. We strongly recommend using pencils ( $2 \mathrm{~B}$ or color) during the mapping exercise with key informants, as pencil cannot be erased by moisture or rain, can be easily corrected and is sufficiently visible for digitizing the map after fieldwork.

This drafting paper is generally available in 20 or $50 \mathrm{~m}$ rolls in stationery shops. The drafting paper needs to be prepared in advance, and cut to A0 size to correspond to the base map. Two copies of the base map on drafting paper need to be prepared prior to fieldwork. 


\section{Checklist of materials}

The following materials should be assembled prior to fieldwork. It is best to buy them in the capital city, since some materials are not available in smaller rural towns:

a. 1 set of maps (base map, copy of base map and most recent satellite image) for each of the villages to be surveyed

b. 1 roll of drafting paper (as a backup)

c. permanent markers of different colors to draw the main features on the copy of the map on drafting paper d. pencils (2B or color) with erasers in abundance (fix an eraser on each pencil using masking tape so as not to lose it during fieldwork)

e. at least 2 cutters

f. 1 large pair of scissors

g. at least 2 rulers (30 $\mathrm{cm}$ long)

h. 2 rolls of masking tape ( $1 \mathrm{~cm}$ wide)

i. 2 or 3 plastic tubes to protect the base maps, satellite images and the map on drafting paper once drawn

j. 1 calculator to calculate corresponding locations of GPS points on the base map. 


\section{Mapping activity with key informants in the small discussion group}

\subsection{Preparing a copy of the base map on drafting paper before starting the activity:}

Time needed: about $1 / 2$ hour per copy of the base map on drafting paper.

This map should be drafted before going to the field sites, although it is possible to do it at the beginning of the fieldwork. The steps are as follows:

- Overlay the drafting paper on the base map and use masking tape to fix the base map and the drafting paper to a table (Figure 1).
- Add any landmark or feature to the drafting paper from the base map, which will help later to overlay the drafting paper map on the base map during the small group discussion with key informants. These features will help orient the researchers and participants who are drawing on the drafting paper during the group discussions, and this map will serve as a backup if the base map is lost or degraded.

- All landmarks (rivers, settlements, roads) should be documented by using permanent markers of different colors (e.g. black for roads and villages, blue for rivers). The village boundaries should be marked with pencil (2B) as they may change after the first mapping exercise during the

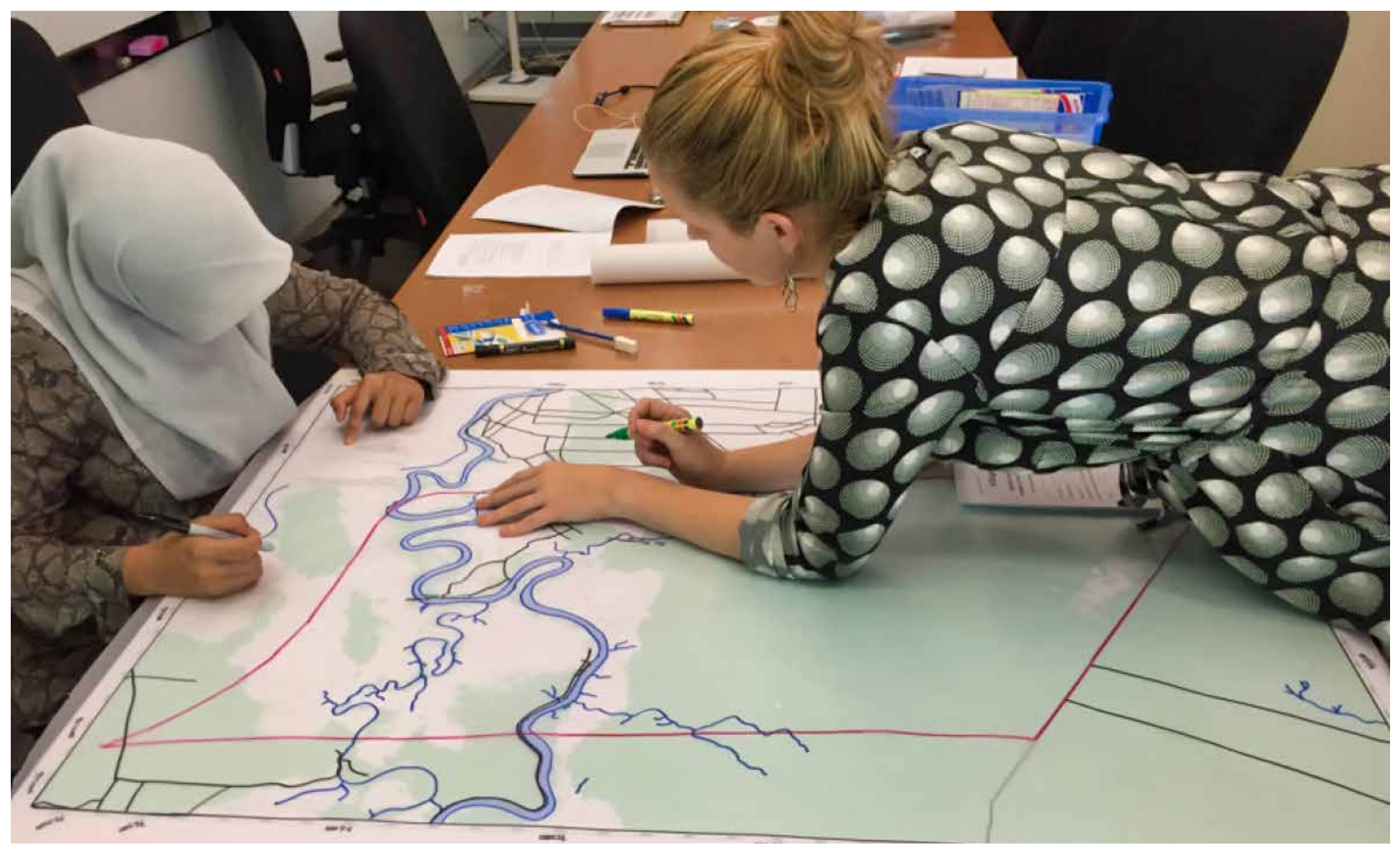

Figure 1. Preparing a copy of the base map on drafting paper.

Note: Adding basic features and landmarks, with the base map used as a background (Credit: Manuel Boissière) 
small group discussion. Add the names of the different features whenever possible (names of villages, rivers, etc.).

- Either draw an X mark on the 4 corners of the map, or draw the frame of the map (this makes it easier to overlay with the base map later, which already has a frame), and add the geographical coordinates in UTM as prepared on the base map by the GIS specialist. These coordinates can be useful in case maps get mixed up, and in case a feature for which there are GPS coordinates needs to be added on the map (e.g. market location).

\subsection{Adding basic information on the copy of the base map on drafting paper:}

Time needed: about 10 minutes per copy of the base map on drafting paper.

Using pencils, draw a rectangle (e.g. $10 \times 20 \mathrm{~cm}$ ) in an unobtrusive part of the map and include the following information:

a. name of village and REDD+ initiative

b. start and end date of the mapping exercise

c. name of field research supervisor/enumerators performing the mapping exercise.

The original base map is kept in case the drafting paper map gets lost or destroyed or if another map is needed. Before going to the field sites, prepare at least two copies of the base map on drafting paper: one for land tenure and areas under dispute; and a second as the base for a clean version of the map resulting from the mapping exercise.

\subsection{Introducing the activity to key informants:}

Clearly explain to the key informants what the map will be used for, and what it will not be used for. The map will not be used for any official uses such as land demarcation, and will not be shared with those outside the research team, such as the private sector, local governments or REDD+ implementers. Explain clearly what mapping activity will be done during this small group discussion, and in the subsequent larger village and women's meetings. Explain that any use of the map (e.g., in future scientific publications) will maintain the anonymity of the village, or will need prior approval from villagers if the village location or name is revealed. Names of key informants of the mapping exercise will be noted for internal purposes but will be kept anonymous in publications. Allow some time for questions and for addressing concerns.

\subsection{Familiarizing key informants with the map:}

When starting the small group discussion, make sure everyone understands the base map; ask them to indicate the village center and check whether everyone recognizes the different features and landmarks.

\subsection{Asking key informants to update the map:}

Using masking tape, secure the base map to a flat place (e.g. school table, on a flat floor or on a table/ floor with a background of flipcharts if there are any irregularities on the table/floor). Place the drafting paper on top of the base map and align the drafting paper and the map using the features previously added to the drafting paper. Keep the high-resolution satellite image/map at hand on the table in case it is needed during the exercise for supporting or checking the corrections made by key informants. The activity can start.

Ask the key informants to change/add any landmark that may be wrong or missing. Start with the village boundaries (see Section 1B.5 of the Village questionnaire). As mentioned earlier, these boundaries were estimated and georeferenced during previous surveys but it is good to check them again and correct if necessary. Ask participants to identify the important locations, names of the different sub-village units or settlements, main roads, main rivers and other water bodies. This copy of the base map on drafting paper will be used during the rest of the exercise by overlaying it on the base map.

\subsection{Asking key informants to answer the Village survey questions:}

The objective is to collect data that provide answers to the relevant questions in the Village questionnaire: 
- Locate the nearest road (Section 1C.24 and 1C.25 of the Village questionnaire).

- Locate the nearest market (Section 1C.28 of the Village questionnaire). If the market is outside the zone covered by the map and too far to be reached during the survey, then a small description about the market location (including the name of the location; see Section 1C.28a of the Village questionnaire) will be added to the questionnaire sheet. A GPS position of the market should be taken whenever possible.

- Identify de jure and de facto land tenure categories applying to each part of the village territory.

- Identify areas with restricted vs open access (Table 5 of the Village questionnaire).

- Identify areas of land dispute (Section 5 of the Village questionnaire).

Explain again what will be asked of the respondents. Use the $\mathrm{B} 2$ pencil to draw on the map, with a code (color, symbol or pattern of your choice) for the different tenure categories. The codes to be used need to be decided before the exercise starts. Mark on the map where the nearest market is located, if visible on the map. Make sure that all key informants agree upon the answers before adding anything to the map. It is better if one of the key informants can draw the features, land tenure categories, etc. on the drafting paper, but if there is no volunteer then the field research supervisors or the enumerators can do the drawing (Figure 2).

\subsection{Finalizing the map:}

Make sure no one wants to add anything to the map or correct what has been drawn (Figure 3). Add on the map with a marker the names of the key informants, the date, the village name and the name of the activity (refer to the Village questionnaire for that). Also add a legend, with all the color/pattern codes used during the mapping exercise clearly identified (see an example of a legend in Figure 4). Take a picture of the map (Figure 3). Information on land tenure and areas of dispute will be on the same copy of the base map on drafting paper.

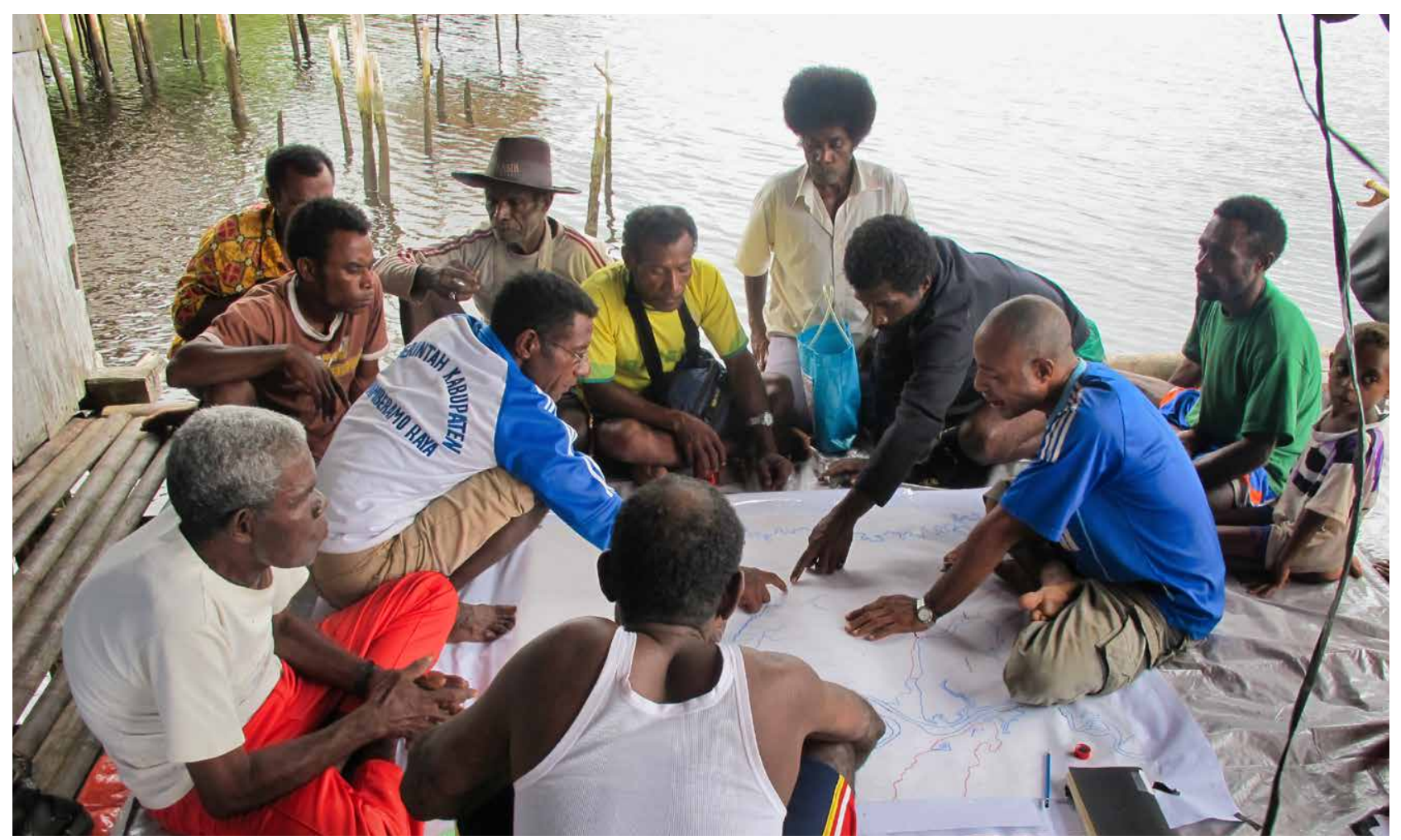

Figure 2. Drawing landscape features with villagers on the copy of the base map using drafting paper. Credit: Manuel Boissière 


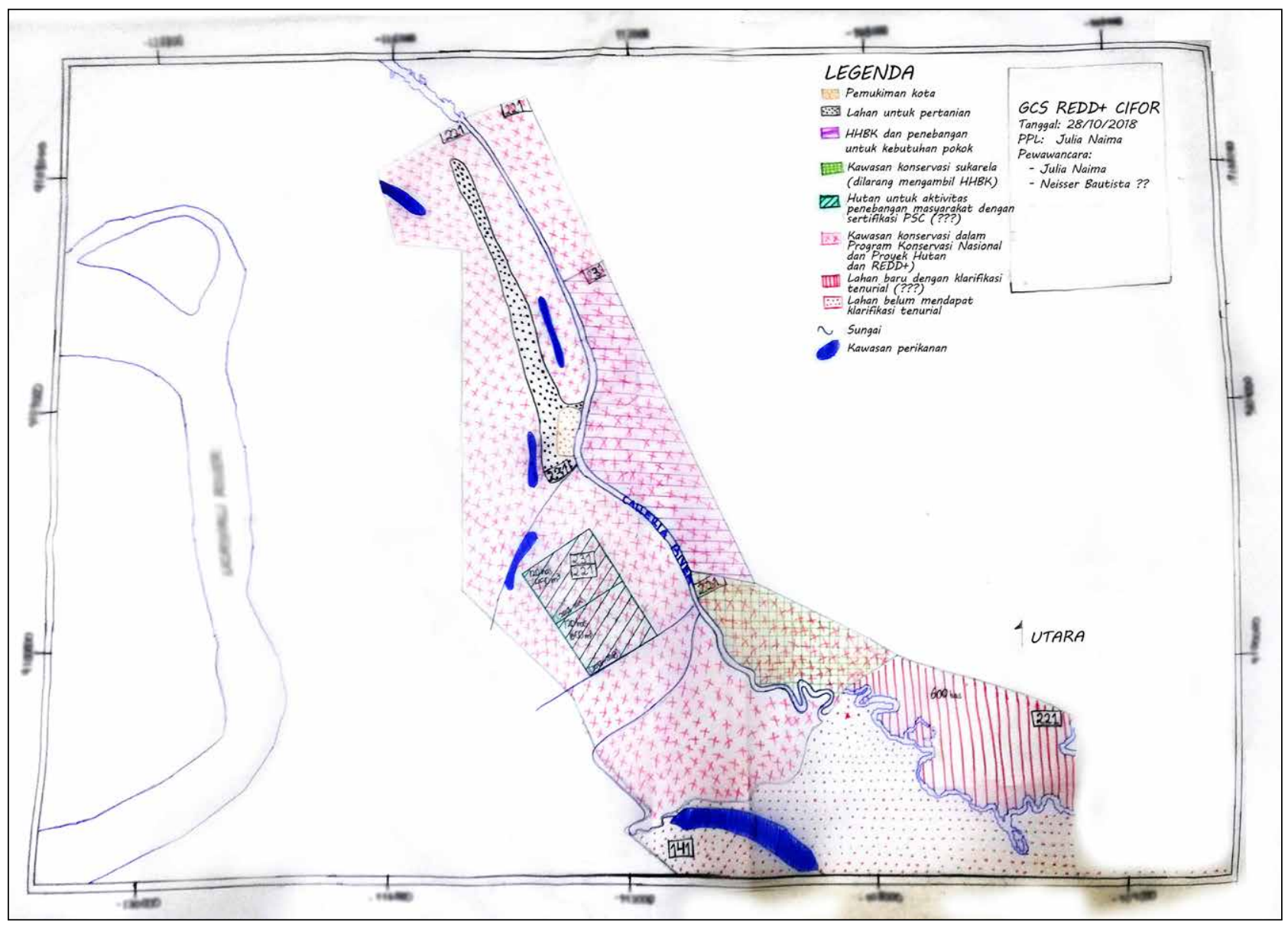

Figure 3. A land tenure map on drafting paper.

Credit: Julia del Carmen Naime Sanchez Henkel

Figure 4. An example of a figure legend.

Note: Add a legend directly on the clean map that includes all the features from the base map and those drawn during the mapping exercise. Use colors and patterns consistently throughout the exercise. Credit: Vivi Selviana

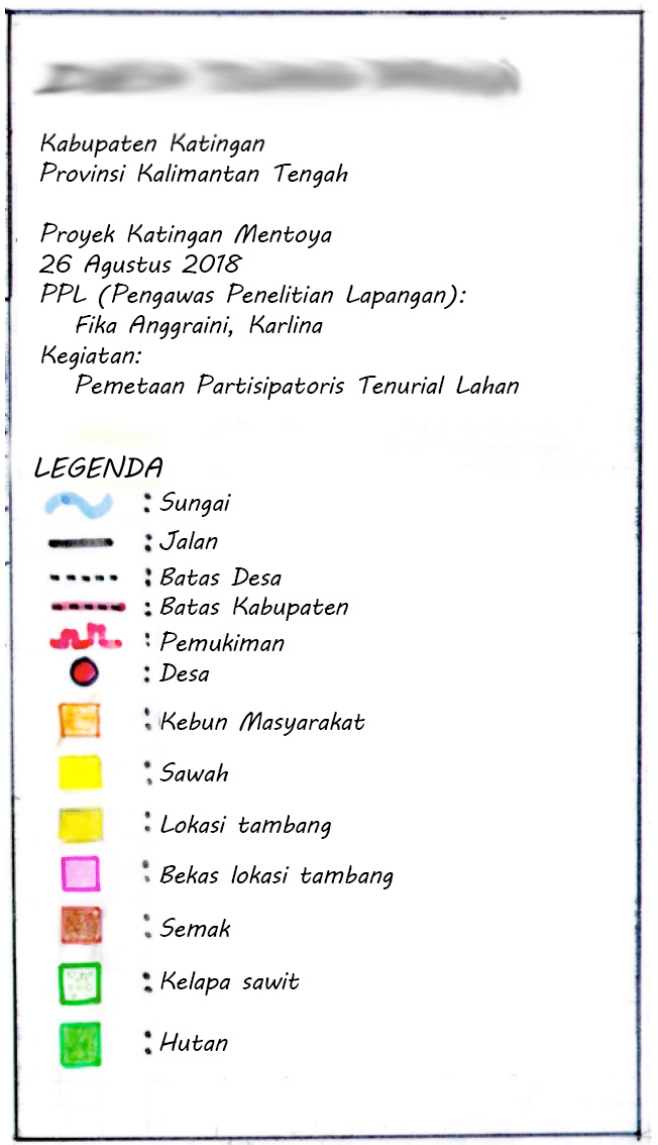




\section{Mapping activities during village and women's meetings}

For GCS REDD+, the objective of the mapping activities during the village and women's meetings is to use the maps developed during the discussion with key informants to collect further information on:

- forest cover changes within the last 2 years under different tenure arrangements

- changes in forest quality (degradation/ enrichment) within the last 2 years under different tenure arrangements.

These refer to Tables 7A and 7B of the Village questionnaire and Tables $1 \mathrm{C} 2$ and $1 \mathrm{C} 3$ of the Women's questionnaire.

These village and women's meetings ideally happen a day after the small group discussion with key informants, since they will use the map resulting from the key informant discussion.

\subsection{Before starting the activity with the meeting participants:}

Make a clean copy/version of the map developed with key informants during the small group discussion with them on a new sheet of drafting paper, because features drawn during that first exercise may not be neat (Figures 5 and 6 ).

On the clean copy, be careful to reproduce exactly the same map as the one developed with key informants during the small group discussion. Do not use permanent marker to reproduce information that was initially drawn using color or black pencil. The reason is that participants at the village or women's meetings may want to modify something on the clean map, which the permanent marker would not allow. Another reason is to distinguish data entered in the field (i.e. with pencil) from data generated by a GIS specialist. As the GIS specialist will be the one digitizing all the maps post-fieldwork, it is important that the parts drawn by villagers are discernable from the original base map features, to avoid mistakes and confusion.

\subsection{Preparation of the activity:}

As for the previous mapping activity with key informants, clearly explain to participants of the village and women's meetings what the map will be used for, and what it will not be used for (not for any official use, not for land demarcation, and not to be used by the private sector, REDD+ implementers etc.). Explain clearly to the participants how the maps will be used during the meeting. Explain that any use of the map (e.g., in future scientific publications) will maintain the anonymity of the village, or will need prior approval from villagers if the village location or name is revealed. Names of key informants of the mapping exercise will be noted for internal purposes but will be kept anonymous in publications. Allow some time for questions and for addressing concerns. Even if the participants in the village and women's meetings do not make any corrections or updates to the maps previously developed with key informants, it is still necessary to provide this same information.

\subsection{Familiarizing the participants with the map and requesting updates:}

The same approach should be used as that in the previous small group discussion with key informants, but can be quicker unless someone wants to correct something major on the map. Familiarize participants with all map features, including those developed (e.g. land tenure types) during the previous mapping exercise. Ask for updates or corrections as needed. 


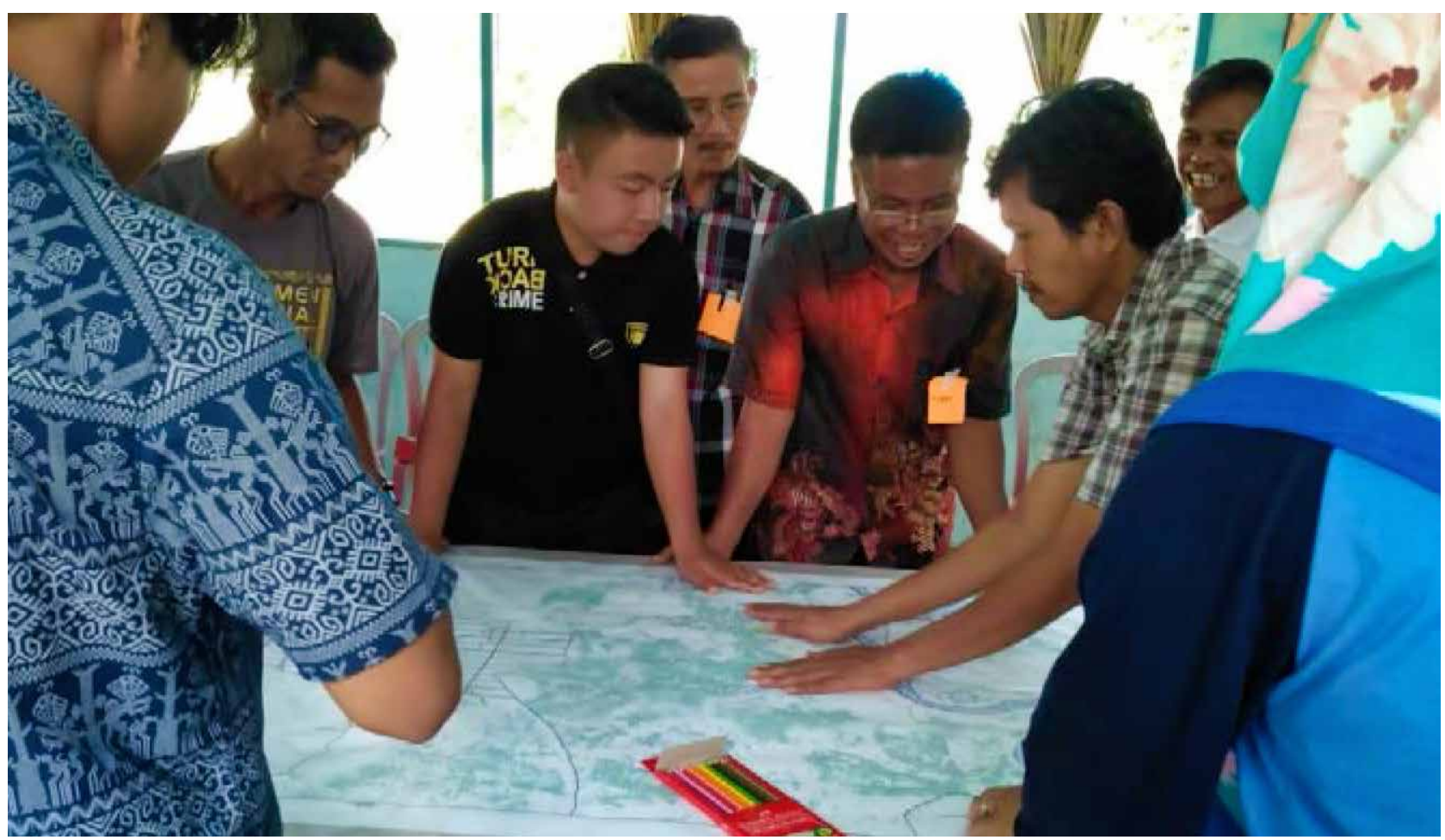

Figure 5. Participatory mapping process.

Credit: Vivi Selviana

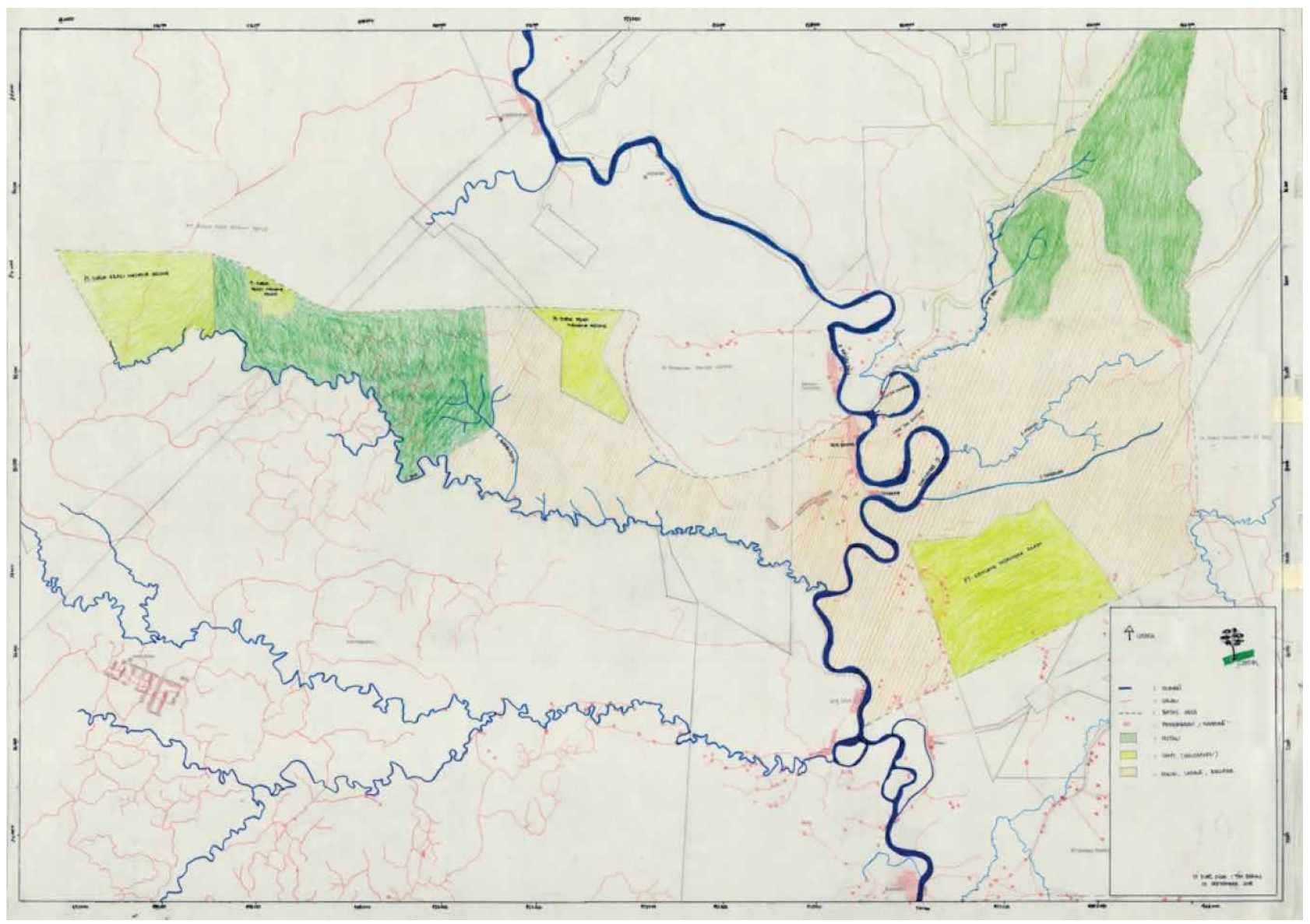

Figure 6. Clean map.

Note: This map is based on the one developed during a small group discussion, with information on tenure provided. Credit: Andini Desita Ekaputri 


\subsection{Asking the respondents to answer the survey questions:}

As mentioned earlier, for GCS REDD+, the questions asked during the village and women's meetings are related to changes in forest cover and forest quality. Use the different tenure types identified during the small group discussion to ask the survey questions. No new map needs to be developed at this stage, since any necessary corrections or updates were solicited at the beginning of the meeting. The map from the satellite image can be used at this stage to crosscheck information on forest clearing.

\subsection{After the group discussion:}

The enumerators will use the results (forest cover/quality changes) to estimate the area under each land tenure category, and fill out answers to the corresponding questions in the Village and Women's questionnaires. 


\section{Finalizing the maps after fieldwork}

Keep the copies of the base map made on drafting paper with key informants in a protective plastic tube. At the end of fieldwork, bring them to a place where they can be scanned and sent to the GIS specialist who will digitize them and integrate each map as one of the different layers that constitute the maps of each site. This will allow the GIS specialist to provide the area (in hectares) that corresponds to each land tenure category, the distance to the nearest market and road (in $\mathrm{km}$ ), and the areas (in hectares) under dispute.

Figure 7 summarises the steps of the village mapping exercise.

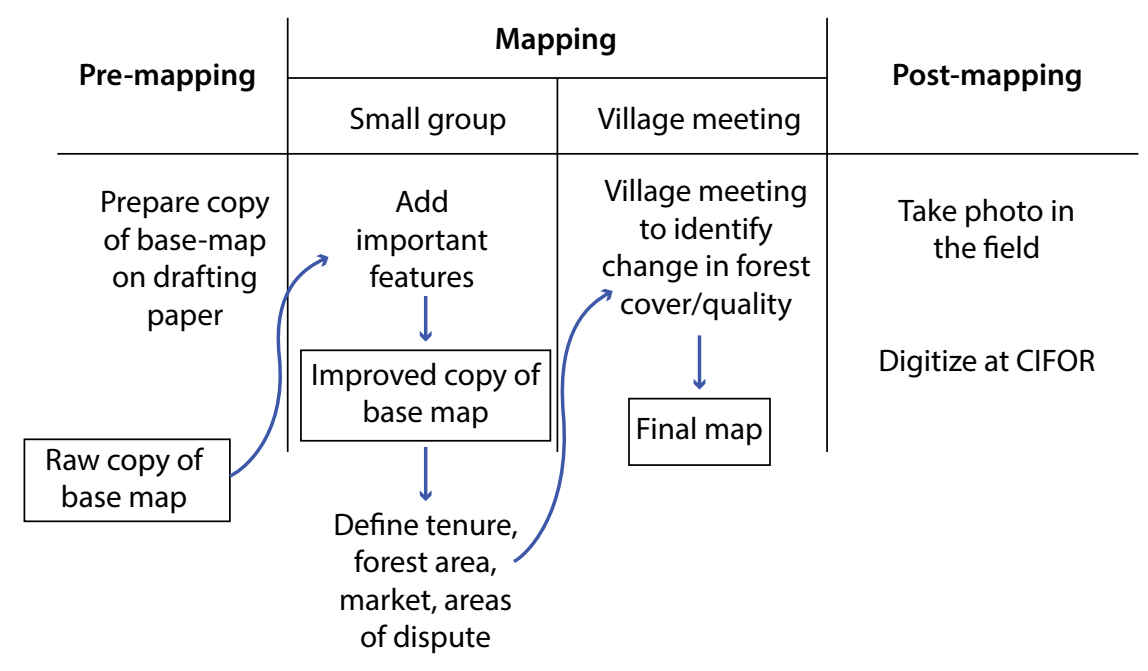

Figure 7. Workflow for the village mapping exercise. 


\section{References}

Anau N, Corbett J, Iwan R, van Heist M, Limberg G, Sudana M and Wollenberg E. 2003. Do communities need to be good mapmakers? Policy Brief. Jakarta, Indonesia: CIFOR.

Boissière M, Liswanti N, Padmanaba $\mathrm{M}$ and Sheil D. 2007. People Priorities and Perceptions. Towards Conservation Partnership in Mamberamo. Bogor, Indonesia: Center for International Forestry Research (CIFOR).

Boissière M, Sassen M, Sheil D, van Heist M, de Jong W, Cunliffe R, Wan M, Padmanaba M, Liswanti N, Basuki I, et al. 2010. Researching local perspectives on biodiversity in tropical landscapes: lessons from ten case studies. In Lawrence A, ed. Taking Stock of Nature : Participatory Biodiversity Assessment for Policy, Planning and Practice. Cambridge, UK: Cambridge University Press. 113-41.

[CIFOR] Center for International Forestry Research. 2017. Global Comparative Study on $R E D D+$. Bogor, Indonesia: CIFOR. Accessed 1 March 2019. www.cifor.org/gcs

Kingsolver A, Boissière M, Padmanaba M, Sadjunin E and Balasundaram S. 2017. Cultural and participatory mapping. In Brunn SD and Dodge M, eds. Mapping Across Academia. Dordrecht: Springer Netherlands. https://doi.org/10.1007/978-94-024-1011-2
Padmanaba M, Boissière M, Sumantri $\mathrm{H}$ and Achdiawan R. 2012. Perspectives on collaborative land use planning in Mamberamo Raya Regency, Papua, Indonesia: Case studies from Burmeso, Kwerba, Metaweja, Papasena, and Yoke. Project Report. Bogor, Indonesia: CIFOR. Sheil D, Puri RK, Basuki I, van Heist M, Wan M, Liswanti N, Rukmiyati, Sardjono MA, Samsoedin I, Sidiyasa K et al. 2002. Exploring biological diversity, environment, and local peoples perspectives in forest landscapes: Methods for a multidisciplinary landscape assessment. Bogor, Indonesia: Center for International Forestry Research.

Sunderlin W, Larson AM, Duchelle AE, Sills EO, Luttrell C, Jagger P, Pattanayak SK, Cronkleton P, Ekaputri AD, de Sassi C, et al. 2016. Technical guidelines for research on REDD+ subnational initiatives. Bogor, Indonesia: Center for International Forestry Research (CIFOR). https://doi. org/10.17528/cifor/006009

van Heist M. 2000. Participatory mapping of village territories. Bogor, Indonesia: Center for International Forestry Research (CIFOR). 


This document is meant for researchers, field research supervisors and enumerators who would like guidance on developing maps with the participation of local communities. It is part of the Global Comparative Study on REDD+ (GCS REDD+) conducted by CIFOR with funding from multiple donors.

Participatory mapping represents a way of documenting land use and tenure arrangements across regions. It is also a way to learn about local perceptions of the landscape, and local people's perspectives of forests and land management. These technical guidelines are based on CIFOR's longterm experience with the use of participatory mapping in research.

In GCS REDD+, the participatory mapping exercise is done at the village level during focus group discussions to learn about village boundaries, tenure, areas under dispute, access, and markets. Base maps are developed from satellite images prior to going to the field. Final maps are digitised so that areas corresponding to the different land uses, land cover, and land tenure categories can be extracted for subsequent analyses. The participatory maps are used to help develop a common understanding of a territory with villagers and other local stakeholders. 